В результате будет получена когнитивная модель педагогической ситуации, верификация которой позволит определить возможные варианты развития педагогической ситуации и повысить эффективность процесса обучения с использованием индивидуальных особенностей инструментария когнитивной организации каждого обучающегося.

\section{Список литературы:}

1. Axelrod R. The Structure of Decision: Cognitive Maps of Political Elites. Princeton. University Press, 1976.

2. Дахин А.Н. Педагогическое моделирование: монография. Новосибирск: Изд-во НИПКиПРО. 2005. $230 \mathrm{c}$.

3. Корноушенко Е.К. Моделирование ситуаций с использованием «расщепленных» когнитивных карт. М.: ИПУ РАН. 2007. С. 137-141.

4. Можаров М.С. Педагогическое моделирование в рамках когнитивного подхода как метод структурного исследования педагогической деятельности // Педагог. Сибирский межвузовский журнал. 1999. № 7. C. 54-57.
5. Когнитивная психология: уч. для вузов / под ред. В.Н. Дружинина, Д.В. Ушакова. М.: ПЕР СЭ, 2002. $480 \mathrm{c}$.

6. Гончарова И.А. Подготовка будущих инженеров к использованию инструментальных программных средств при решении и моделировании научных и учебных задач: дис. ... канд. пед. наук. Калуга. 2005. $248 \mathrm{c}$.

7. Софронова Н.В., Горохова Р.И. Моделирование педагогических систем: монография. Чебоксары: Чувашский гос. пед. ун-т, 2011. 174 с.

8. Гулидова И.В., Гуревич Л.И., Можаров М.С. Понятийные модели образовательной области // Качество образования: концепции, проблемы оценки, управление: сб. тез. науч.-практ. конф. Новосибирск, 1998. C. 43-46.

9. Шапошникова Т.Л., Подольская О.Н., Пастухова И.П. Теория графов как математическая основа решения социально-педагогических задач // Научные труды КубГТУ. 2016. № 8. С. 370-384.

10. Сергеев С.Ф. Когнитивная педагогика: пользовательские свойства инструментов познания // Школьные технологии. 2011. № 2. С. 35-41.

\title{
THEORETICAL JUSTIFICATION OF PEDAGOGICAL SITUATIONS COGNITIVE MODELING
} (C) 2018

Kamaleeva Alsu Raufovna, doctor of pedagogical sciences, leading researcher

Gruzkova Svetlana Yurevna, candidate of technical sciences, senior researcher Institute of Pedagogics, Psychology and Social Problems (Kazan, Russian Federation)

Abstract. The following paper deals with the application of methodology of pedagogical situations cognitive modeling, which is considered by the authors as a process consisting of six consecutive and interconnected stages. The first stage is a formulation of the purpose and the corresponding tasks. The second stage provides collecting, systematization and analysis of a pedagogical situation with the subsequent allocation of the major factors influencing development of the situation and determination of interrelation between them, i.e. creation of a cognitive map. At the third stage a focused count is created as a result of accounting of the cause and effect chains reflecting the system of interaction between the educational process subjects and allowing to form a pedagogical theory on the basis of basic person study categories: consciousness, thinking, knowledge, understanding, etc. The fourth stage assumes combination of the cognitive map and the focused count in a uniform cognitive model of the studied pedagogical situation. The fifth stage is focused on a real pedagogical situation cognitive model adequacy check i.e. on its verification. The last sixth stage allows to define possible options of a pedagogical situation development by a cognitive model, to find ways and mechanisms of a situation impact.

Keywords: cognitive modeling; pedagogical situation; cognitive map; cognitive model; educational process; interaction of subjects; cognitive student organization; intelligence; cognitive styles; memory; attention; consciousness; thinking; knowledge; understanding.

\section{ПРИКЛАДНЫЕ ОСНОВАНИЯ УПРАВЛЕНИЯ ПРОЦЕССОМ ВОСПИТАНИЯ ФИЗИЧЕСКОЙ КУЛЬТУРЫ ЛИЧНОСТИ}

(C) 2018

Коровин Сергей Семенович, доктор педагогических наук, профессор кафедры теории и методики спортивных дисциплин, адаптивной физической культуры и медико-биологических основ физического воспитания Оренбургский государственный педагогический университет (2. Оренбург, Российская Федерачия)

Аннотация. Обеспечение качества школьного физического образования как системы направленного использования ценностей физической культуры обусловлено эффективностью деятельности учителя (равно как и всех субъектов школы) по реализации управленческих действий в отношении оптимизации функционирования этой системы, ее целостности и устойчивости в достижении основополагающей цели - воспитание физической культуры обучающихся. При этом сама управленческая деятельность как система предусматривает, в свою очередь, определенную этапность управленческой работы в отношении осуществления на каждом из этапов соответствующего содержания управленческих действий. Так, на основе существующих представлений о внутришкольном управлении, опыта управления процессами освоения физической культуры в воспитании интегративного личностного качества физической культуры обучающегося установлены следующие 
этапы управленческой деятельности и их основное содержание: получение информации о состоянии процесса физического образования; диагноз состояния объекта (предмета) управления и прогноз развития физического образования; определение цели организации и реализации содержания физического образования, а также задач, обеспечивающих достижение цели - воспитания физической культуры обучающихся; выработка решения по управленческой деятельности на основе определения противоречий и проблемы в отношении воспитания физической культуры обучающихся; осуществление всех видов планирования, отражающих то, как процесс освоения физической культуры будет реализовываться в конкретных условиях; разработка содержания деятельности (физкультурно-спортивной) по освоению физической культуры, включающего совокупность умений и навыков, знаний, подлежащих воспитанию (формированию) и отражающих физическую культуру личности; организация деятельности, включающая совокупность действий по оптимизации физкультурно-спортивной деятельности в отношении обучения, воспитания и развития личностных и двигательных потребностей и способностей; контроль (комплексный) образовательной деятельности (медикобиологическая и психолого-педагогическая его формы); сбор и обработка результатов образовательной деятельности; осуществление действий по коррекции цели, содержания планирования, содержания физкультурно-спортивной деятельности и организационных мероприятий по оптимизации процесса физического образования.

Ключевые слова: физическое образование обучающихся школьников; ценности физической культуры; этапы, структура и содержание управленческой деятельности; воспитание физической культуры субъекта; виды управленческих действий.

Современная школа в настоящее время реализует достаточно многогранную образовательную деятельность в отношении формирования культурологических характеристик личности обучающихся, что в существенной мере обусловлено требованиями ФГОС общего образования [1]. Такая образовательная практика вызывает некоторые затруднения в реализации основополагающих целевых ориентиров, что обусловлено смещением ценностных ориентаций обучающихся, некоторыми материально-техническими затруднениями современной школы, недостатком внимания органов управления образования к непростой деятельности учительского корпуса. Настоящим обусловливается необходимость и актуальность овладения преподавателем (учителем, тренером) основами управления процессами освоения ценностей физической культуры в ходе физического образования. Вполне очевидно, что овладение учителем физической культуры основами управленческой деятельности позволит оптимально включиться в целостный процесс управления школой и, главное, оптимизировать собственную управленческую деятельность в отношении повышения эффективности физического образования и физкультурно-спортивной деятельности (ФСД) в части реализации главной его цели - воспитание на всех этапах онтогенеза обучающихся их физической культуры.
В специальной литературе «управление» определяют как функцию любых (прежде всего социальных) систем, с реализацией которой обеспечивается поддержание оптимального режима деятельности этой системы для реализации установленных цели и программы [2]. Именно за счет соответствующего управления достигается (в существенной мере) сохранение структуры управляемой системы и оптимальный режим ее (системы) деятельности, функционирования. В сфере педагогического знания управление есть взаимодействие субъектов педагогического процесса на основе реализации его закономерностей для достижения социально и личностно значимой цели [3, с. 421; 4, с. 464]. Таким образом, основными действиями в составе управления можно считать выработку решения, целеполагание, организацию (в широком, относительно масштабном смысле), контроль, регуляцию объекта управления в соответствии с целью, аналитическую работу [5, с. 315-355].

При этом структура (в педагогике - отражение состава структурных компонентов и их взаимосвязей по обеспечению целостности, устойчивости функционирования какой-либо системы) [6] управления внутришкольным физическим образованием в воспитании физической культуры личности в самом общем виде может быть представлена следующим образом (рис. 1).

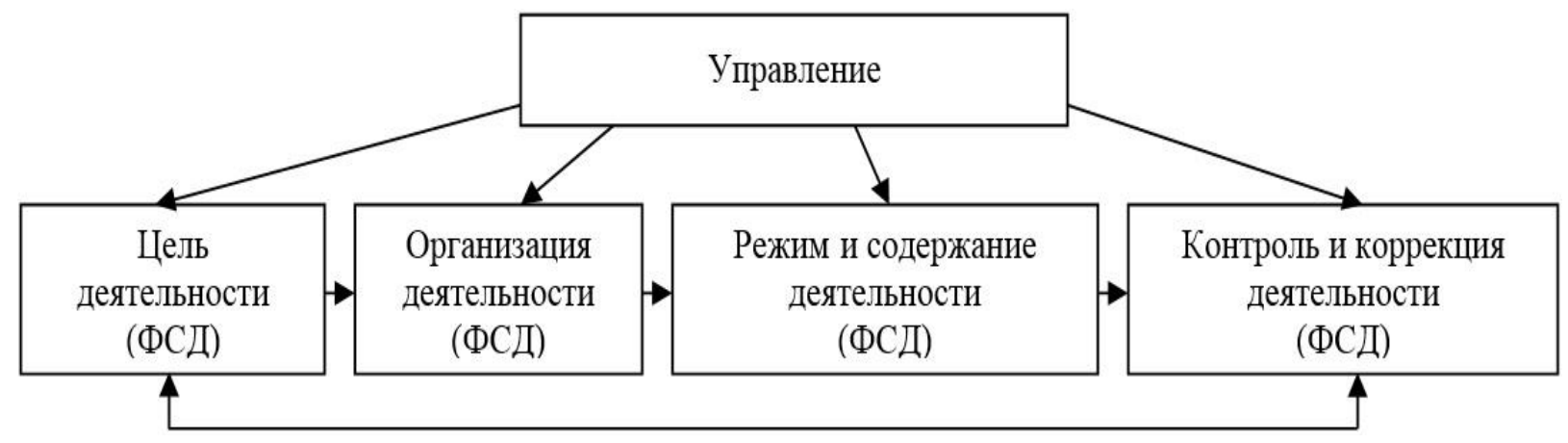

Рисунок 1 - Структура (общая) управления социальными системами (включая физическое образование)

Классическая структура управления распространяется практически на все процессы освоения физической культуры, находит применение и в системе спортивной подготовки [7, с. 23].
Более утилитарное определение управления в сфере физической культуры можно представить как специально смоделированную деятельность, направленную на оптимизацию функционирования физиче- 
ского образования обучающихся (как частность) и процессов освоения физической культуры (в целом).

Причем это касается и системы спортивной подготовки [8, с. 431]. Таким образом, цель управления физическим образованием - оптимизация функционирования системы процессов освоения физической культуры; объект - оптимизация процессов взаимодействия субъектов физического образования, а предмет - физическая культура обучающихся.

Тем не менее управленческая деятельность необходимо присутствует (как правило, осознанно или нет) в работе учителя физической культуры (он осуществляет внутришкольное управление физическим образованием) и определяется как деятельность по оптимизации взаимодействия участников физического образования (детей и педагогов) для достижения установленного результата (цели) [9].

Однако в связи с временными характеристиками управленческой работы учителя в практике деятельности школы определены следующие виды управления [10]:

- управление этапное; с его реализацией обеспечивается оптимизация процесса физического образования в течение учебного года (макроцикла спортивной подготовки);

- управление текущее; в ходе него достигается эффективность образовательной практики по освоению определенного программного материала (раздела школьной программы, учебной четверти программы периода спортивной подготовки);

- управление оперативное, которое имеет направленность на оптимизацию процессов освоения конкретной ФСД в пределах одного учебного занятия (урока, тренировки или соревнования).

На основе сложившихся представлений о понятийно-категориального аппарате управления, исходя их методологических представлений об управлении и психолого-педагогического (методических) оснований, можно определить процесс управления внутришкольным физическим образованием как поэтапный $[11 ; 12 ; 13$, с. $17 ; 14]$ :

- получение (сбор и обработка) информации о состоянии процесса физического образования;

- диагноз состояния объекта (предмета) управления и прогноз развития физического образования;

- определение цели организации и реализации содержания физического образования, а также задач, обеспечивающих достижение цели - воспитание физической культуры обучающихся;

- выработка решения по управленческой деятельности на основе определения противоречий и проблемы в отношении воспитания физической культуры обучающихся;

- осуществление всех видов планирования, отражающих, как процесс освоения физической культуры будет реализовываться в конкретных условиях;

- разработка содержания деятельности (физкультурно-спортивной) по освоению физической культуры, включающего совокупность умений и навыков, знаний, подлежащих воспитанию (формированию) и отражающих физическую культуру личности [13, c. 40-41];
- организация деятельности, включающая совокупность действий по оптимизации физкультурноспортивной деятельности в отношении обучения, воспитания и развития личностных и двигательных потребностей и способностей;

- контроль (комплексный) образовательной деятельности (медико-биологическая и психологопедагогическая его формы) [7; 15; 16];

- сбор и обработка результатов физического образования (ФСД);

- осуществление действий по коррекции цели, содержания планирования, содержания физкультурно-спортивной деятельности и организационных мероприятий по оптимизации процесса физического образования, то есть далее - новый цикл управления (в идеале) [2, с. 380; 17, с. 704-705].

Таким образом, системные представления об управлении внутришкольным физическим образованием можно выразить таким образом (табл. 1).

После реализации всех управленческих действий, зарегистрированных на 9 и 10 этапах управления физическим образованием, по сути, начинается новый цикл управления (начиная с 4 этапа) на новом качественном уровне.

В заключение следует выделить основные виды деятельности спортивного педагога в управлении физическим образованием:

- проводить диагностику и оценивание сформированности физической культуры обучающихся; сущностных характеристик базовой культуры личности;

- выявлять цели и задачи физического образования обучающихся; для их успешной реализации организовывать взаимодействие субъектов образовательного процесса;

- осуществлять планирование всех видов в воспитании физической культуры школьников;

- разрабатывать содержание ФСД в ходе процесса физического образования;

- осуществлять организационные действия в отношении реализации содержания ФСД в воспитании физической культуры обучающихся;

- осуществлять комплексный контроль, учет и коррекцию процессов освоения физической культуры;

- оценивать результативность процессов направленного использования ценностей физической культуры и своей деятельности в этом отношении.

Здесь же следует оговориться, что независимо от вида управления все обозначенные этапы, основные направления и содержание управленческой деятельности так или иначе проявляются (в полном объеме или в сокращенном) и необходимы к реализации.

При этом существенным фактором обеспечения качества управления является взаимодействие участников физического образования, их взаимопонимание, согласованность действий и заинтересованность в модернизации физического образования обучающихся для достижения основополагающей цели воспитание физической культуры личности. 


\section{Таблица 1 - Характеристика этапов управления физическим образованием}

\begin{tabular}{|c|c|c|}
\hline $\begin{array}{l}\text { № } \\
\Pi / \Pi\end{array}$ & Этап управления & Направленность и содержание управленческой работы \\
\hline & $\begin{array}{l}\text { Получение (сбор и } \\
\text { обработка) инфор- } \\
\text { мации об исходном } \\
\text { состоянии процесса } \\
\text { физического обра- } \\
\text { зования }\end{array}$ & $\begin{array}{l}\text { 1. Выявление специфики образовательного учреждения: } \\
\text { - педагогические кадры и их компетентность (включая преподавателей иных учеб- } \\
\text { ных дисциплин); } \\
\text { - выявление спортивных традиций школы (образовательной организации); } \\
\text { - изучение состояния материально-технической базы и ее соответствия установлен- } \\
\text { ным нормативным требованиям и цели управления. } \\
\text { 2. Выявление коллективного отношения (иных преподавателей) к физической куль- } \\
\text { туре (физкультурно-спортивной деятельности - ФСД). } \\
\text { 3. Определение актуальности физической культуры (ФСд) в системе школьного об- } \\
\text { разования. } \\
\text { 4. Нахождение критериев диагностики и оценки физического образования. } \\
\text { 5. Выявление особенностей взаимосвязи и взаимодействия с родителями, спонсора- } \\
\text { ми, управления образования и т.п. } \\
\text { 6. Учет собранной информации. }\end{array}$ \\
\hline & $\begin{array}{l}\text { Диагноз состояния } \\
\text { объекта (предмета) } \\
\text { управления и про- } \\
\text { гноз деятельности }\end{array}$ & $\begin{array}{l}\text { 1. Разработка (подбор) частных методик диагностики и оценки сформированности } \\
\text { физической культуры обучающегося. } \\
\text { 2. Определение качества исходного состояния сформированности физической куль- } \\
\text { туры личности обучающихся в части характеристик физического развития, двига- } \\
\text { тельных умений и навыков, двигательных качеств, знаний, потребностей и мотивов, } \\
\text { характеристик базовой культуры. } \\
\text { 3. Определение основных направлений («на сейчас») в использовании ценностного } \\
\text { потенциала физической культуры в воспитании и(или) обучении и(или) развитии } \\
\text { основных характеристик физической культуры обучающихся. }\end{array}$ \\
\hline & $\begin{array}{l}\text { Определение цели } \\
\text { организации и реа- } \\
\text { лизации содержания } \\
\text { физического обра- } \\
\text { зования, а также за- } \\
\text { дач, обеспечиваю- } \\
\text { щих достижение це- } \\
\text { ли - воспитание фи- } \\
\text { зической культуры } \\
\text { обучающихся } \\
\end{array}$ & $\begin{array}{l}\text { 1. Утверждение установленной цели и задач физического образования с педагогиче- } \\
\text { ским коллективом школы. } \\
\text { 2. Установление взаимодействия - согласования с обучающимися цели, основных } \\
\text { задач и методических направлений реализации ФСД в воспитании физической } \\
\text { культуры школьников. }\end{array}$ \\
\hline & $\begin{array}{l}\text { Выработка решения } \\
\text { по управленческой } \\
\text { деятельности на ос- } \\
\text { нове определения } \\
\text { противоречий и } \\
\text { проблемы в отно- } \\
\text { шении воспитания } \\
\text { физической культу- } \\
\text { ры обучающихся }\end{array}$ & $\begin{array}{l}\text { 1. Реализация мероприятий по формированию потребностно-мотивационой сферы } \\
\text { школьников на ФСД в освоении физической культуры. } \\
\text { 2. Разработка научной гипотезы (моделей реализации решения) по воспитанию фи- } \\
\text { зической культуры обучающихся. } \\
\text { 3. Согласование решения с коллегами и администрацией; реализация мероприятий } \\
\text { по обеспечению их участия в реализации ФСд. } \\
\text { 4. Создание необходимых педагогических и организационных педагогических } \\
\text { условий: } \\
\text { - материальных и санитарно-гигиенических; } \\
\text { - методическая подготовленность всех участников образовательного процесса в } \\
\text { сфере физической культуры; } \\
\text { - создание теоретико-методических оснований разработки содержания целенаправ- } \\
\text { ленной ФСд (подбор средств, основных методов их реализации, организационных } \\
\text { форм и принципов использования физической культуры. } \\
\text { 5. Согласование решения с обучающимися; нахождение сферы их участия в реали- } \\
\text { зации решения. }\end{array}$ \\
\hline & $\begin{array}{l}\text { Осуществление всех } \\
\text { видов планирова- } \\
\text { ния, отражающих } \\
\text { то, как процесс } \\
\text { освоения физиче- } \\
\text { ской культуры бу- } \\
\text { дет реализовываться } \\
\text { в конкретных усло- } \\
\text { виях и во времен- } \\
\text { ном аспекте }\end{array}$ & $\begin{array}{l}\text { 1. Разработка видов плана: } \\
\text { - перспективного (на один учебный год и(или) макроцикл); } \\
\text { - этапного (раздел школьной программы или учебная четверть); } \\
\text { - краткосрочного (отдельное занятие; их серия). } \\
\text { 2. Соблюдение основных требований к планированию, что проявляется в комплекс- } \\
\text { ном характере обучающих, воспитательных и развивающих воздействий; в возмож- } \\
\text { ности модификации и «перестройки» плана в связи с обстоятельствами; в безуслов- } \\
\text { ной реалистичности содержания планов; во взаимодействии внутренних и внешних } \\
\text { факторов физического образования; системности (преемственность и последова- } \\
\text { тельность реализации содержания ФСД; конкретности материала планирования. }\end{array}$ \\
\hline & \begin{tabular}{|l} 
Разработка содер- \\
жания деятельности \\
(физкультурно- \\
спортивной) по
\end{tabular} & $\begin{array}{l}\text { 1. Определение системы принципов (общих социальных, общеметодических и спе- } \\
\text { цифических), регламентирующих физкультурно-спортивную деятельность в воспи- } \\
\text { тании физической культуры школьников } \\
\text { 2. Подбор средств физической культуры и регламента их реализации, обусловлива- } \\
\text { ющих достижение цели (физические упражнения, средовые и гигиенические факто- }\end{array}$ \\
\hline
\end{tabular}




\begin{tabular}{|c|c|c|}
\hline & $\begin{array}{l}\text { освоению физиче- } \\
\text { ской культуры, } \\
\text { включающего сово- } \\
\text { купность умений и } \\
\text { навыков, знаний, } \\
\text { подлежащих воспи- } \\
\text { танию (формирова- } \\
\text { нию) и отражающих } \\
\text { физическую культу- } \\
\text { ру личности }\end{array}$ & $\begin{array}{l}\text { ры, вспомогательные и дополнительные средства). } \\
\text { 3. Выбор методов, обеспечивающих направленное использование средств (игровой, } \\
\text { соревновательный и группа методов строго-регламентированного упражнения). } \\
\text { 4. Определение организационных форм физкультурно-спортивной деятельности } \\
\text { (освоения физической культуры), обеспечивающих качество усвоения содержания } \\
\text { физкультурно-спортивной деятельности (классно-урочной и всех реальных вне- } \\
\text { урочных). } \\
\text { 5. Разработка способов преемственности в подборе средств и методов физкультур- } \\
\text { но-спортивной деятельности и последовательности их реализации. } \\
\text { 6. Подготовленность преподавательского (учительского) корпуса к реализации со- } \\
\text { держания ФСД и физического образования. }\end{array}$ \\
\hline & $\begin{array}{l}\text { Организация дея- } \\
\text { тельности, включа- } \\
\text { ющая совокупность } \\
\text { действий по опти- } \\
\text { мизации физкуль- } \\
\text { турно-спортивной } \\
\text { деятельности в от- } \\
\text { ношении обучения, } \\
\text { воспитания и разви- } \\
\text { тия личностных и } \\
\text { двигательных по- } \\
\text { требностей и спо- } \\
\text { собностей }\end{array}$ & $\begin{array}{l}\text { 1. Повторное (при необходимости) разъяснение основной цели и определяющих ее } \\
\text { решение задач ФСд. } \\
\text { 2. Развитие системы мотивов на освоение физической культуры и ФСД всех участ- } \\
\text { ников этих процессов (вполне естественно, что каждого «на своем поле»). } \\
\text { 3. Обеспечение оптимального (доверительного и партнерского) взаимодействия } \\
\text { преподавателей и обучающихя. } \\
\text { 4. Реализация координирующих действий и деятельности всех субъектов физиче- } \\
\text { ского образования (учителей физической культуры, учителей-предметников, управ- } \\
\text { ленческого аппарата школы, родительского корпуса и т.п.). } \\
\text { 5. Создание должных материально-технических и санитарно-гигиенических (быто- } \\
\text { вых) условий для реализации содержания физического образования и ФСд. } \\
\text { 6. Реализация мер по восполнению научно-методической подготовленности препо- } \\
\text { давательского корпуса в вопросах теории и методики физического образования. } \\
\text { 7. Определение и создание необходимых условий для целенаправленной реализации } \\
\text { дидактического обеспечения физического образования и ФСд. } \\
\text { 8. Апробация методов и частных методик диагностики, регистрации, измерения и } \\
\text { оценки состояния физической культуры личности. }\end{array}$ \\
\hline & $\begin{array}{l}\text { Контроль (ком- } \\
\text { плексный) образо- } \\
\text { вательной деятель- } \\
\text { ности (медико- } \\
\text { биологическая и } \\
\text { психолого- } \\
\text { педагогическая его } \\
\text { формы) }\end{array}$ & $\begin{array}{l}\text { 1. Диагностика состояния физической культуры личности (наиболее характерных } \\
\text { для реальной практики школьного физического образования): } \\
\text { - освоенность системы знаний в сфере физической культуры; } \\
\text { - качество сформированных мотивов и потребностей в освоении физической культуры; } \\
\text { - двигательная подготовленность, регистрируемая по состоянию двигательных ка- } \\
\text { честв и качеству-количеству сформированных двигательных умений и навыков; } \\
\text { - состояние физического развития и основных систем жизнеобеспечения (функцио- } \\
\text { нальная подготовленность). } \\
\text { 2. Выявление качественных характеристик действия административно- } \\
\text { управленческого аппарата школы и иных субъектов физического образования, а } \\
\text { также взаимодействия всех субъектов ФСд. } \\
\text { 3. Реализация основных требований комплексного контроля, отражающих его си- } \\
\text { стемность, своевременность и объективность, комплексность. } \\
\text { 4. Регистрация и учет всех показателей контроля на основе сравнения данных «до» } \\
\text { и «после». }\end{array}$ \\
\hline & $\begin{array}{l}\text { Сбор и обработка } \\
\text { результатов физиче- } \\
\text { ского образования } \\
(Ф С Д)\end{array}$ & $\begin{array}{l}\text { 1. Осуществление диагностики и оценки: } \\
\text { - качества взаимодействия всех субъектов физического образования; } \\
\text { - состояния ценностных ориентаций всех участников ФСД и физического образо- } \\
\text { вания; } \\
\text { - качества сформированности физической культуры личности школьников; } \\
\text { - организации процессуальной составляющих обучающих, воспитательных и разви- } \\
\text { вающих воздействий; } \\
\text { - процессуальной и результативной деятельности преподавательского корпуса; } \\
\text { - направленности субъектов физического образования и ФСД на расширение и } \\
\text { упрочение мательально-технической оснащенности процессов освоения физической } \\
\text { культуры, а также на восполнение личностной методической подготовленности. } \\
\text { 2. Сопоставление результатов образовательной деятельности по воспитанию физи- } \\
\text { ческой культуры обучающихс (исходных данных и итоговыми). } \\
\text { 3. Учет и осмысление результатов физического образования и ФСд. }\end{array}$ \\
\hline 10 & $\begin{array}{l}\text { Осуществление дей- } \\
\text { ствий по коррекции } \\
\text { цели, содержания } \\
\text { планирования, со- } \\
\text { держания физкуль- } \\
\text { турно-спортивной } \\
\text { деятельности и ор- } \\
\text { ганизационных ме- } \\
\text { роприятий по опти- } \\
\text { мизации процесса } \\
\text { физического обра- } \\
\text { зования }\end{array}$ & $\begin{array}{l}\text { 1. Реализация мероприятий по «переводу» у обучающихся мотива освоения физиче- } \\
\text { ской культуры на цель. } \\
\text { 2. Коррекция основного содержания физического образования в отношении воспи- } \\
\text { тания компонентов физической культуры обучающихся. } \\
\text { 3. Поиск и внедрение новых технологий физического образования. } \\
\text { 4. Коррекция имеющихся и принятие мер по обеспечению должных взаимодействий } \\
\text { субъектов ФСД. }\end{array}$ \\
\hline
\end{tabular}




\section{Список литературы:}

1. Федеральный государственный образовательный стандарт среднего общего образования. Утвержден Приказом Министерства образования и науки Российской Федерации от 17.05.2012 г. № 413 // Российская газета. №5812 (139). 21.06.2012.

2. Философский словарь / под ред. И.Т. Фролова. М.: Политиздат, 1980. 445 с.

3. Педагогика: учебное пособие / В.А. Сластенин, И.Ф. Исаев, А.И. Мищенко, Е.П. Шиянов. М.: Школа-Пресс, 1998. 512 с.

4. Педагогика физической культуры / под ред. С.Д. Неверковича. М.: Физкультура и спорт, 2006. 528 с.

5. Педагогика: учебное пособие / В.Г. Рындак, Н.В. Алехина, И.В. Власюк и др. / под ред. В.Г. Рындак. М.: Высшая школа, 2006. 495 с.

6. Коджаспирова Г.М., Коджаспиров А.Ю. Словарь по педагогике. М.: ИКЦ «МарТ»; Ростов-наДону: Издательский центр «МарТ», 2005. 448 с.

7. Основы управления подготовкой юных спортсменов / под ред. М.Я. Набатниковой. М.: Физкультура и спорт, 1982. $280 \mathrm{c.}$

8. Терминология спорта. Толковый словарь спортивных терминов / сост. Ф.П. Суслов, Д.А. Тышлер. М.: СпортАкадемПресс, 2001. 480 с.
9. Дуранов М.Е., Чернецкий Ю.М. Общая педагогика. Челябинск: ЮУрГУ, 1999. 186 с.

10. Платонов В.Н. Общая теория подготовки спортсменов в олимпийском спорте. К.: Олимпийская литература, 1997. 583 с.

11. Дуранов М.Е. Профессионально-педагогическая деятельность и исследовательский подход к ней. Челябинск: ЧГАКИ, 2002. 276 с.

12. Загвязинский В.И., Атаханов Р. Методология и методы психолого-педагогического исследования. М.: Академия, 2001. 208 с.

13. Краевский В.В., Бережнова Е.В. Методология педагогики: новый этап. М.: Академия, 2008. 400 с.

14. Сластенин В.А., Каширин В.П. Психология и педагогика. М.: Академия, 2001. 480 с.

15. Матвеев Л.П. Теория и методика физической культуры. М.: Физкультура и спорт, 1991. 543 с.

16. Холодов Ж.К., Кузнецов В.С. Теория и методика физической культуры и спорта. М.: Академия, 2014. $480 \mathrm{c}$.

17. Философский энциклопедический словарь / гл. ред: Л.Ф. Ильичев, П.Н. Федосеев, С.М. Ковалев, В.Г. Панов. М.: Сов. энциклопедия, 1983. 840 с.

\section{APPLIED BASES OF THE PERSON PHYSICAL CULTURE EDUCATION PROCESS MANAGEMENT} (C) 2018

Korovin Sergey Semenovich, doctor of pedagogical sciences, professor of Theory and Methodology of Sports, Adaptive Physical Culture and Medico-Biological Foundations of Physical Education Department Orenburg State Pedagogical University (Orenburg, Russian Federation)

Abstract. The quality of school education as a system of the directional usage of the physical culture values is conditionally provided through the effectiveness of the teacher's activities (as well as by all the school's subjects) in realization of the management actions with regards to this system functioning optimization, its integrity and stability in the process of the base aim achievement - students' physical culture education. Meanwhile the management activity itself as a system stipulates, in its turn, for the definite stages of the management work with regards to the fulfillment a corresponding content of the management actions. So, based on the existing notions about the internal school management system as well as on the experience in management the process of physical education in the bringing up a student's physical culture, the following management activities stages and their main content are defined: collection and processing (analysis, synthesis) information about the object of management (physical education); diagnosis of the state of the object (subject) of management and the activity forecast, establishment of the aim (the anticipation of the results in physical culture and sports activities), private goals in the process of students' physical culture teaching, management decision taking (the combination of the mental operations and actions, that define a problematic situation, its transfer to the task, formation of the physical culture and sports activities motives and hypothesis about the means of its decision); planning (foreseeing the way how the physical education process will be developed in time); working out a physical culture and sports activities content (system regulation of the elements and processes, that form the subject or phenomenon; the content of physical culture and sports activities - the system of knowledge, movement abilities and skills, experience of the creative value-oriented activity, that provide for the personality's physical culture formation); activity organization (as a combination of actions for regulation and co-ordination of subject-object physical culture and sports activities in teaching, education and development of the personality); control (complex) of education activity (its biomedicine and psycho-pedagogical forms); collection and processing of education activities results; correction of the aim, planning, content and the processes of physical culture and sports activities and physical education organization.

Keywords: physical education of students; values of physical culture; stages; structure and content of management activities; bringing up subject's physical culture; types of management actions.

\section{ТЕОРЕТИЧЕСКИЕ АСПЕКТЫ ПРОБЛЕМЫ ИНТЕРНАЦИОНАЛИЗАЦИИ ВЫСШЕГО ОБРАЗОВАНИЯ В СОВРЕМЕННОМ МИРЕ}

Кузовенкова Ксения Олеговна, преподаватель кафедры экономики и менеджмента Филиал Самарского государственного технического университета в г. Новокуйбышевске (2. Новокуйбышевск, Самарская область, Российская Федерация)

Аннотация. В данной работе рассматриваются теоретические аспекты понятийного аппарата интернационализации высшего образования с точки зрения отечественных и зарубежных ученых. Автор приходит к 